\title{
LAS GLOSAS DE REICHENAU
}

Manuel A. Quirós R.

\begin{abstract}
This study presents certain lexical characteristics of the Reichenau Glosses, one of the most important glossaries of Medieval Latin, and it analyses, paradigmatically, the lexical differentiation which existed between the two essential diastratic varieties of Latin: cultivated Latin ("lemma"); and, the spontaneous language ("interpretamentum"), the prelude to nascent Romance, especially French.
\end{abstract}

\section{INTRODUCCION}

El Glossarium biblicum codicis augiensis LVIII, mejor conocido bajo la denominación de "Glosas de Reichenau", es uno de los glosarios medioevales más importantes para el conocimiento del latín en el siglo VIII y como señaiador de tendencias románicas, sobre todo, del idioma francés.

Augiensis procede de Augia Magna o Augia Dives, nombre latino de Reichenau, isla del Lago de Constanza (Bodensee, en alemán).

El manuscrito más antiguo data del siglo VIII; fue redactado en el Monasterio de Corbie (Corbia), en Picardía, norte de Francia (1); pero sólo se conserva una copia de segundo grado en la Biblioteca de Karlsruhe, Alemania Federal.

$\mathrm{El}$ texto estuvo guardado largo tiempo en la abadía benedictina de Reichenau (de donde la otra denominación) fundada por San Fermín en 724, y seguidamente, durante el Período Carolingio, un importante centro de cultura medioeval, como tantos otros monasterios benedictinos.

Las Glosas de Reichenau fueron descubiertas por A. Hotzmann en 1863, y publicadas por F. Diez en 1865.

\section{FUENTES DEL GLOSARIO DE REICHENAU}

Las Glosas de Reichenau se derivan de una gran cantidad de fuentes: entre las más importan- tes están las Etymologiae de Isidoro de Sevilla por intermedio de otra compilación, el Abavus Maior, que suministran 700 glosas, el Glossarium Ansileubi y escritores tardíos en latín gálico de los siglos IV y V.

\section{DIVISION DEL GLOSARIO DE REI- CHENAU}

El Glosario de Reichenau posee una clara división bipartita:

\section{a) Glossarium Biblicum}

Esta parte es la más antigua y glosa 3.152 "items" de la Vulgata a partir del Libro del Génesis, cuya etimología es dada en los siguientes términos: "Genesis dictus eo quod teneat exordium generationis" (2). Luego dan inicio las explicaciones que, para ser comprendidas, en concepto del autor deben ser explicadas por otras palabras cuotidianas y más corrientes.

La primera parte se extiende hasta la mitad del Segundo Libro de los Macabeos; mas de repente salta a los Evangelios y a los Hechos de los Apostoles; después se devuelve al punto de interrupción en los Macabeos, continúa con los libros de Daniel, Jonás y Jeremías y concluye con los Salmos.

b) Ejemplos de aparición de las palabras en el Glossarium Biblicum 


\begin{tabular}{ll}
\multicolumn{1}{c}{ Lemma } & Interpretamentum \\
25 Pulcra & bella \\
55 optimum & valde bonum \\
60 semel & una vice \\
274 flare & suflare \\
261 cecinit & cantavit \\
285 pignus & wadius \\
336 sartago & patella \\
342 crura & tibia \\
460 caementariis & macionibus \\
461 concidit & taliavit \\
463 onager & asinus salvaticus \\
474 torax & brunia \\
476 iecore & ficato \\
544 uvas & racemos \\
551 si vis & si voles \\
567 ita & sic
\end{tabular}

Traducción

(Genesis 12,11) bella

(Genesis 18,7) muy bueno

(Genesis 18,27) una vez

(Exodus 10,19) soplar

(Exodus 15,1) cantó

(Exodus 22,26) prenda

(Levit. 2,5) sartén

(Levit, 11,21) tibia

(Reges II,4,7) albañiles

(Reges IV ,22,6) cortó

(Job 6,5) asno silvestre

(Job 41,17) coraza

(Tobías 6,5) hígado

(Matth. 7,16) uvas

(Matth. 8,2) si quieres

(Matth. 12,22) así (3). c) Glossarium Alphabeticum

La segunda parte, más reciente, expone en orden alfabético, también palabras y expresiones bíblicas; además, vidas de santos y otros escritos religiosos mediante un lenguaje cotidiano, pero culto.

\section{Ejemplos}

$\begin{array}{lll}\text { Lemma } & \text { Interpretamentum } & \text { traducción } \\ \text { 22 Arena } & \text { sabulonem } & \text { arena } \\ \text { 45 atram } & \text { nigram } & \text { negra } \\ 483 \text { detegere } & \text { discooperire } & \text { descubrir } \\ 723 \text { Gallia } & \text { Frantia } & \text { Francia } \\ 732 \text { hiems } & \text { ibernus } & \text { invierno } \\ 785 \text { induti } & \text { vestiti } & \text { vestidos (sust.) } \\ 893 \text { mares } & \text { masculus } & \text { varón } \\ 1178 \text { preter (praeter) } & \text { excepto } & \text { fuera de } \\ 1238 \text { pulempta } & \text { farina } & \text { harina } \\ 1509 \text { solitudo } & \text { heremus } & \text { solitario } \\ 1569 \text { sus } & \text { porcus } & \text { cerdo } \\ 1619 \text { tugurium } & \text { cavanna } & \text { cabaña } \\ 1640 \text { vespertiliones } & \text { calves sorices } & \text { vampiros } \\ 1708 \text { utere } & \text { usitare } & \text { usar (4) }\end{array}$

\section{ACLARACIONES SOBRE LOS INTERPRE-} TAMENTA.

La mayoría de los interpretamenta anteriormente presentados son sinónimos dè los "items" del lemma; por lo tanto, en términos generales, el Augiensis es monolingüe: id est, todos los lemma, en latín culto, están aclarados, casi siempre, con interpretamenta extraídos del mismo latín, pero de un latín menos refinado para personas "menos cultas", con el fin de aclararles las palabras difí- ciles y otras demasiado clásicos (permítase la expresión), cuyo recuerdo se había borrado de la mente popular, $y$, por tanto, se habían hecho incomprensibles en la Francia norteña del siglo IX.

Los interpretamenta restantes están en celta, griego, o germánico; todos más conocidos y comprensibles. Los germánicos están más de acuerdo con la nueva realidad político-cultural románicogermánica que acababa de ser instaurada por obra de los francos, quienes tuvieron un gran respeto 
por la tradición latinorrománica de la antigua $G a$ -

Ilia, por lo cual, desde el punto de vista de la lengua, Francia es más bien un país romance y no germánico, aunque los préstamos francones, cuantiosos e importantes, constituyan el principal superestrato del francés.

\section{ALGUNAS PALABRAS FRANCONAS EN EL GLOSARIO DE REICHENAU}

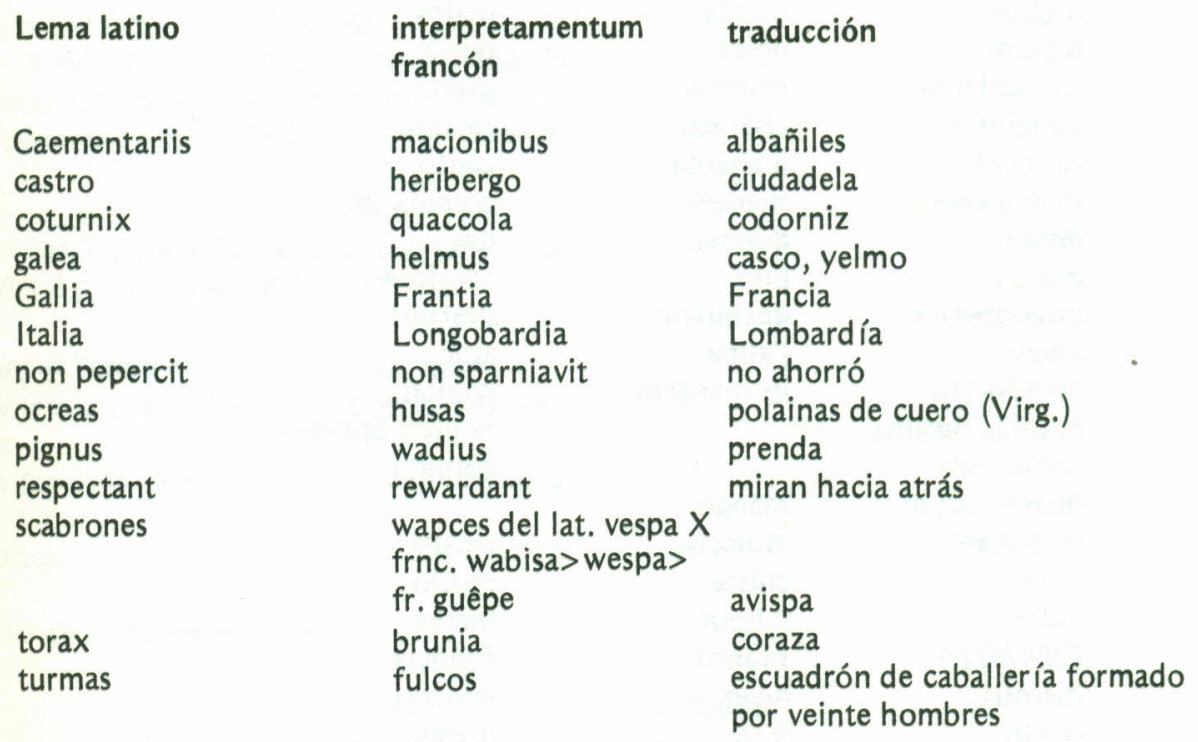

La glosa más significativa, pues manifiesta claramente la nueva realidad histórica instaurada por los francos, es la No. 5 de la lista precedente, cuyo lemma es Gallia y el interpretamentum, Frantia, un sustantivo latinizado de origen francón.

\section{ALGUNOS CELTISMOS EN LAS GLOSAS DE REICHENAU}

\begin{tabular}{|c|c|c|}
\hline $\begin{array}{l}\text { Bracis } \\
\text { pallium }\end{array}$ & $\begin{array}{l}\text { bragas } \\
\text { drappum }\end{array}$ & $\begin{array}{l}\text { fr. braies, esp. bragas } \\
\text { fr. drapeau (bandera), } \\
\text { esp. trapo }\end{array}$ \\
\hline rostrum & beccus & fr. bec, esp. pico, \\
\hline
\end{tabular}

7. ALGUNOS HELENISMOS EN LAS GLO. SAS DE REICHENAU

$\begin{array}{lll}\text { lecur } & \text { ficatum } & \text { fr. foie, esp. higado } \\ \text { ictus } & \text { colpus } & \text { fr.coup, esp. golpe } \\ \text { in loculum } & \text { in sarcophagum } & \text { en el sepulcro } \\ \text { rupem } & \text { petram } & \text { fr. pierre, esp. piedra } \\ \text { solitudo } & \text { heremus } & \text { solitario } \\ \text { vituperant } & \text { blasphemant } & \text { blasfeman }\end{array}$

\section{ALGUNOS "ITEMS" DEL GLOSARIO DE REICHENAU CON LEMMA E INTERPRE. TAMENTA LATINOS, PRELUDIO, ESTE, DEL GALORROMANICO}

Muchos interpretamenta del glosario en consideración preludian el galorromance, especialmente la "langue d'oill" o francés: 


\begin{tabular}{|c|c|c|c|}
\hline Lemma latino & $\begin{array}{l}\text { interpretamentum } \\
\text { latino }\end{array}$ & francés & español \\
\hline Abio (abeo) & vado & (je) vais & voy \\
\hline adversum & contra & contre & contra \\
\hline anus & vetulae & des vieilles & viejas \\
\hline ager & campus & champ & campo \\
\hline ago & facio & je fais & hago \\
\hline amne & fluvio & fleuve & río \\
\hline arbusta & arbriscellus & arbrisseau & arbolito \\
\hline arena & sabulonem & sable & arena \\
\hline articulos & digitos & doigts & dedos \\
\hline atram & nigram & noire & negra \\
\hline caseum & formaticum & fromage & queso \\
\hline castra & castellum & château & castillo \\
\hline cecinit & cantavit & il chanta & cantó \\
\hline comesta & manducata & mangée & comida (part.) \\
\hline dare & donare & donner & dar \\
\hline deinceps & postea & puis & (des)pués \\
\hline detegere & discooperire & découvrir & descubrir \\
\hline dilexi & amavi & j'aimai & amé \\
\hline edunt & manducant & ils mangent & comen \\
\hline egregia & nobilia, óptima & & nobles, óptimos \\
\hline esum & $\begin{array}{l}\text { comestum } \\
\text { manducatum }\end{array}$ & mangé & comido \\
\hline favillam & scintillam & étincelle & chispa \\
\hline femur & coxa & cuisse & muslo \\
\hline fervet & bullit & il bout & hierve \\
\hline GALLIA & FRANTIA & France & Francia \\
\hline hieme & ibernus & hiver & invierno \\
\hline iecore & ficato & foie & hígado \\
\hline infecunda & sterelis & stérile & estéril \\
\hline id & hoc & ce (prov. oc) & esto \\
\hline in foro & in mercato & marché & mercado \\
\hline in ore & in bucca & dans la bouche & en la boca \\
\hline is & $\mathrm{il} / \mathrm{le}$ & le & el \\
\hline ita & sic & si & si \\
\hline litus & ripa: riparia & rivière & rivera \\
\hline luxit & ploravit & il pleura & lloró \\
\hline mares & masculus & mâle & macho \\
\hline necis & mortis & derivado:noyer & de la muerte \\
\hline olim & antea & fr. ant. ainz & antes \\
\hline onager & asinus silvaticus & sauvage & salvaje \\
\hline optimos & meliores & meilleurs & mejores \\
\hline pueros & infantes & enfants & niños \\
\hline pallium & drappum & drapeau & bandera \\
\hline pulchra & bella & belle & bella \\
\hline pulempta & farina & farine & harina \\
\hline rerum & causarum & des causes & de las causas \\
\hline & causa & $\begin{array}{l}\text { des choses } \\
\text { cause,chose }\end{array}$ & $\begin{array}{l}\text { de las cosas } \\
\text { causa, cosa }\end{array}$ \\
\hline saniore & plus sano & plus sain & más sano \\
\hline sartago & patella & poêlle & sartén \\
\hline
\end{tabular}




$\begin{array}{llll}\text { semel } & \text { una vice } & \text { une fois } & \text { una vez } \\ \text { singulariter } & \text { solamente } & \text { seulement } & \text { solamente } \\ \text { si vis } & \text { si volles } & \text { si tu veux } & \text { si quieres } \\ \text { sus } & \text { porcus } & \text { porc } & \text { puerco } \\ \text { tugurium } & \text { cavanna } & \text { cabane } & \text { cabaña } \\ \text { umo (humus) } & \text { terra } & \text { terre } & \text { tierra } \\ \text { uva passa } & \text { uva sicca } & \text { raisins sec } & \text { pasa } \\ \text { uvas } & \text { racemos } & \text { raisins } & \text { uvas }\end{array}$

Una posible comparación entre los lemma y los interpretamenta anteriormente considerados haría ver el relativo carácter monolingüe de las Glosas de Reichenau, o más bien, el estado diferenciado de latinidad: uno de un registro "superior" (los lem$\mathrm{ma}$ ), y otro, de un registro "inferior" (los interpretamenta).

\section{ALGUNAS CARACTERISTICAS DEL VO. CABULARIO AUGIENSE}

a) Casi todo el léxico es de procedencia latina.

b) La mayor parte del léxico extranjero es de origen francón.

c) Existen también términos de procedencia celta, y griega.

d) Sustantivos

- Palabras de connotación marcial

$\begin{array}{lll}\text { Castra } & \text { castellum } & \text { fortaleza } \\ \text { ensis } & \text { gladius } & \text { espada } \\ \text { framea (lanza germánica) } & \text { gladius bisacutus } & \text { framea } \\ \text { ictus } & \text { colpus } & \text { golpe } \\ \text { milites } & \text { servientes } & \text { soldados }\end{array}$

- Onomástica zoológica

$\begin{array}{lll}\text { Aper } & \text { salvaticus porcus } & \text { jabalí } \\ \text { coturnix } & \text { quaccola } & \text { codorniz } \\ \text { catulus } & \text { catellus } & \text { cachorro } \\ \text { onager } & \text { asinus salvaticus } & \text { asno silvestre } \\ \text { oves } & \text { berbices } & \text { carnero } \\ \text { passer } & \text { omnis minuta avis } & \text { cualquier ave diminuta } \\ \text { vespertiliones } & \text { calves sorices } & \text { vampiros }\end{array}$

\section{- Toponimia}
Gallia
Frantia
Francia
Italia
Longobardia
Lombardía
- Palabras con un nuevo glosamiento, debido a la la variedad de las fuentes

Callis semita parvula sendero 


$\begin{array}{llllll}\text { semita } & \text { vias } & \text { calles } & \text { luxit } & \text { ploravit } & \text { lloró } \\ \text { pulcra bella } & \text { bella } & \text { non pepercit } & \text { non sparniavit } & \text { no ahorró } \\ \text { venusto } & \text { pulchro vel onesto } & \text { bello u honesto } & \text { sevit } & \text { seminavit } & \text { sembró } \\ \text { specum speluncam } & \text { cueva } & \text { si vis } & \text { si volles } & \text { si quieres } \\ \text { spelunca } & \text { concavata saxa } & \text { peñascos cóncavos } & \text { ulciscere } & \text { vindicare } & \text { vengar } \\ & & \text { utere } & \text { usitare } & \text { usar } \\ \text { - Formas helipticas en el interpretamentum } & \text { vinxit } & \text { ligavit } & \text { ató }\end{array}$

$\begin{array}{lll}\begin{array}{l}\text { Caseum } \\ \text { hieme } \\ \text { iecore }\end{array} & \begin{array}{l}\text { (caseum) formaticum } \\ \text { (tempus) ibernus } \\ \text { (iecur) ficato }\end{array} \\ \text { tum Empleo de diminutivos en el interpretar } \\ \text { Anus } & \text { vetulae } & \text { viejitas } \\ \text { castra } & \text { castellum } & \text { castillo } \\ \text { mares } & \text { masculus } & \text { macho }\end{array}$

-Ampliación del cuerpo fónico

$\begin{array}{lll}\text { Da } & \text { dona } & \text { da (tú) } \\ \text { dem } & \text { donem } & \text { (que) yo dé } \\ \text { flare } & \text { suflare } & \text { soplar } \\ \text { isset } & \text { ambulasset } & \text { hubiera caminado } \\ \text { serunt } & \text { seminant } & \text { siembran }\end{array}$

-Desaparición de la reduplicación verbal

$\begin{array}{lll}\text { Ceciderunt } & \begin{array}{l}\text { caderunt } \\ \text { tangit }\end{array} & \begin{array}{l}\text { cayeron } \\ \text { tetigit }\end{array}\end{array}$

- Metáforas humorísticas en el interpretamentum

$\begin{array}{lll}\text { Comesta } & \text { manducata } & \text { comida (part.) } \\ \text { edunt } & \text { manducant } & \text { comen } \\ \text { in ore } & \text { in bucca } & \text { en la boca }\end{array}$

- Generalizaciones en el interpretamentum

-Desaparición de verbos deponentes

$\begin{array}{lll}\text { Ingredi } & \text { intrare } & \text { entrar } \\ \text { minatur } & \text { manatiat } & \text { amenza } \\ \text { pollicitus est } & \text { promisit } & \text { prometió } \\ \text { transgrediuntur } & \text { transvadunt } & \text { atraviesan }\end{array}$

$\begin{array}{lll}\text { Ager } & \text { campus } & \text { campo } \\ \text { necis } & \text { mortis } & \text { de la muerte } \\ \text { umo (humus) } & \text { terra } & \text { tierra }\end{array}$

e) Adjetivos

- Adjetivación perifrástica

$\begin{array}{lll}\text { Optimum } & \text { valde bonum } & \text { muy bueno } \\ \text { saniore } & \text { plus sano } & \text { más sano }\end{array}$

f) Verbos

\section{-Regularización verbal}

\begin{tabular}{lll}
$\begin{array}{l}\text { Canere } \\
\text { cecinit }\end{array}$ & cantare & cantar \\
cantavit & cantó \\
da & taliavit & cortó \\
dem & dona & dá) \\
difert & donem & (que) yo dé \\
dilexi & elonget & aleja \\
distulerit & amavi & amé \\
emit & reverseverit & habrá dispersado \\
iacere & comparavit & adquirió \\
induti & iactare & echar \\
\hline & vestiti & vestidos (part.)
\end{tabular}

g) Pronombres

-Sustitución del sistema del latín clásico

$\begin{array}{lll}\text { Ab his } & a b \text { istas } & \text { desde éstas } \\ \text { id } & \text { hoc } & \text { esto } \\ \text { is } & \text { ille vel iste } & \text { aquél o éste } \\ \text { cuncti } & \text { omnes } & \text { todos } \\ \text { nemini } & \text { nulli } & \text { a nada }\end{array}$
h) Adverbios
-Sustituciones, en algunos casos perifrástica, de la rica variedad clásica

$\begin{array}{lll}\begin{array}{l}\text { Deinceps } \\ \text { dudum }\end{array} & \begin{array}{l}\text { postea } \\ \text { ante }\end{array} & \begin{array}{l}\text { después } \\ \text { ante }\end{array} \\ \text { furtim } & \text { + per furtum } & \text { furtivamente } \\ \text { ibidem } & \text { + in eodem loco } & \text { en el mismo lugar } \\ \text { ita } & \text { sic } & \text { así } \\ \text { olim } & \text { antea } & \text { antes } \\ \text { semel } & \text { + una vice } & \text { una vez } \\ \text { singulariter } & \text { solamente } & \text { solamente } \\ \text { vicissim } & \text { + per vices } & \text { alternativamente (5) }\end{array}$




\section{i) Preposiciones}

-Pérdida de la variedad preposicional del latín clásico

Adversum contra contra

in occursum eorum in contra illos

j) Fonética

-Alteraciones fonéticas

$\begin{array}{lll}\text { bracis } & \text { bragas } & \text { bragas } \\ \text { Colafis } & \text { colpis } & \text { golpes } \\ \text { culicet (collocet) } & \text { culcet } & \text { coloque } \\ \text { hieme } & \text { ibernus } & \text { invierno }\end{array}$

\section{k) Morfología}

\section{-Alteraciones morfológicas}

Ceciderunt $\begin{aligned} & \text { caderunt } \\ & \text { pes }\end{aligned}$
l) Otros

\section{- Glosas dobles}

\section{Canere} cecinit

cantar

cantó

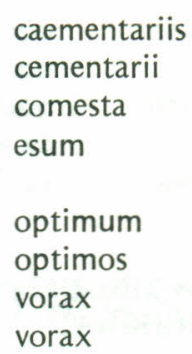

macionibus mationes

manducata

comestum, manducatum

valde bonu

meliores

manducans

manducator albañiles

albañiles

comida (part.) comido (part.)

muy bueno

mejores

el que come

el que come

\section{- Glosas Triples}

$\begin{array}{lll}\text { Crimine } & \text { peccato } & \text { pecado } \\ \text { nefas } & \text { peccatum } & \text { pecado } \\ \text { in scelere } & \text { in peccato } & \text { en pecado }\end{array}$

- Vocabulario latino con aspecto romance

$\begin{array}{lll}\text { Cave } & \text { provide } & \text { cuídate de... } \\ \text { levam } & \text { sinistram } & \text { izquierda } \\ \text { ludebant } & \text { iocabant } & \text { jugaban } \\ \text { obviare } & \text { incontrare } & \text { ir al encuentro } \\ \text { onerati } & \text { carcati } & \text { cargados } \\ \text { aportet } & \text { convenit } & \text { conviene } \\ \text { stabilivi } & \text { firmavi } & \text { consolidé } \\ \text { sublata } & \text { subportata } & \text { soportada }\end{array}$

-Ejemplos de lemma simple y de interpretamentum perifrástico

Calamus
fastigium
grando
opilio
oppidis
poto
pingues

Traducción:

Traducción:

Traducción:

Traducción:

Traducción:

Traducción:

Traducción

precoce uve
Traducción: penna unde litteras scribuntur pluma para escribir pennaculum templi, res alta, uel summa pars edificii, uel altitudo, culmen uel capita montium frontón del templo, la cosa alta o la parte superior del edificio, o altitud, cima o cima de las montañas pluvia mixta cum petris lluvia mezclada con piedras custos ovium vel berbicarius guardián de ovejas o pastor castella uel civitatibus fortaleza o ciudadelas do tibi bibere te doy de beber quae naturaliter grassi sunt quienes son gordos por naturaleza qui ante maturescunt uel calore vel ubertate terre las que maduran antes, ya sea por el calor del sol, ya sea por la fecundidad de la tierra qui a dentes iacet 


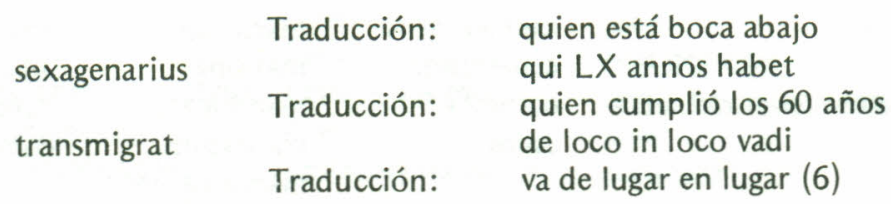

\section{CONCLUSION: IMPORTANCIA LINGUIS . TICA DEL GLOSARIO DE REICHENAU}

E. D. Elcock manifiesta: "Ces glosses...sont pour les études romanes ...d'une valeur qu'on ne peut guere exagérer (7).

La importancia lingüística de las Glosas de Reichenau reside en que presenta, generalmente bajo sinónimos, dos distintas diferenciaciones del latín de la Edad Media y en que los interpretamenta preludian los distintos romances, sobre todo, el idioma francés: "Der wissenschaftliche Wert der Reichenauer Glossen besteht darin, dass sie uns eine Vorstellung geben von dem Zustand der in Nordfrankreich gesprochenen romanische Volksprache, wie wir diese im 8 . Jahrhundert, d. h. noch vor dem Auftretem der ersten Volksprache geschriebener Texte denken müssen" (8).

\section{NOTAS}

(1) A muchos de los monasterios benedictinos el mundo occidental les es deudor de la transmisión, en escritura carolina, de la literatura romana.

(2) El "Génesis" es llamado así por tener el origen de las genealogías.

(3) Ejemplos extraídos de Gerhard Rohıfs, Vom Vulgärlatein zum Altfranzösische, p. 34.

(4) Ejemplos extraídos de Manuel C. Díaz y Díaz, Antología del latín vulgar, ps. 109, 110 y 111.

(5) El signo (+) indica sustitución perifrástica.

(6) Traducción al francés y español hechas por el autor.

(7) Traducción: "Estas glosas...son, para los estudios románicos, de un valor que apenas se podría exagerar". (Traducción del autor).

(8) Traducción: “El valor científico de las Glosas de Reichenau consiste en que nos dan una idea del estado de la lengua romance hablada en el norte de Francia como nos la debemos imaginar en el siglo VIII, es decir aun antes de la aparición de los primeros textos en lengua vulgar" (Traducción del autor).

\section{BIBLIOGRAFIA}

Blanquez Fraile Augustín, Diccionario LatinoEspañol, Ed. Sopena, Barcelona, 1950.

Chaurand Jacques, Introduction à l'histoire au vo.cabulaire français, Bordas, Paris, 1977.

Díaz y Díaz Manuel, Antología del latín vulgar. Ed. Gredos, Madrid, 1962.

Elcock W. D., The romance languages, London, Faber and Faber, 1960.

Lofstedt Leena, Die Reichenauer Glossen, in: Zeitschrift für romanische philologie, Band 85 , Heft 5/6, S. 532-535, Max Niemeyer Verlag, Tübingen.

Macchi Luis, Diccionario de la lengua latina, Editorial Don Bosco, Buenos Aires, 1951.

Monteverdi Angelo., Manuale d'avviamento agli studi romanzi, I, le lingue romanze, ed. VaIlardi, Milano, 1952.

Rohlfs Gerhard, Sermo vulgaris latinus. Vulgärlateinisches Lesebuch, Max Niemeyer Verlag, Tübingen, 1956

Rohlfs Gerhard, Vom Vulyärlatein zum Altfranzösischen, Max Niemeyer Verlag, Tübingen, 1963.

Wolff Philippe, Origen de las lenguas occidentales, 100-1500 d. C., Ediciones Guadarrama S.A., 1971. 